\title{
Time intervals from first symptom to treatment of cancer: a cohort study of 2,212 newly diagnosed cancer patients
}

\author{
Rikke P Hansen ${ }^{1,2^{*}}$, Peter Vedsted ${ }^{1,2}$, Ineta Sokolowski ${ }^{3}$, Jens Søndergaard ${ }^{4}$ and Frede Olesen ${ }^{3}$
}

\begin{abstract}
Background: Delay in diagnosis of cancer may worsen prognosis. The aim of this study is to explore patient-, general practitioner (GP)- and system-related delay in the interval from first cancer symptom to diagnosis and treatment, and to analyse the extent to which delays differ by cancer type.

Methods: Population-based cohort study conducted in 2004-05 in the County of Aarhus, Denmark (640,000 inhabitants). Data were collected from administrative registries and questionnaires completed by GPs on 2,212 cancer patients newly diagnosed during a 1-year period. Median delay (in days) with interquartile interval (IQI) was the main outcome measure.

Results: Median total delay was 98 days (IQI 57-168). Most of the total delay stemmed from patient (median 21 days (7-56)) and system delay (median 55 days (32-93)). Median GP delay was 0 (0-2) days. Total delay was shortest among patients with ovarian (median 60 days (45-112)) and breast cancer (median 65 days (39-106)) and longest among patients with prostate (median 130 days (89-254)) and bladder cancer (median 134 days (93-181)).

Conclusion: System delay accounted for a substantial part of the total delay experienced by cancer patients. This points to a need for shortening clinical pathways if possible. A long patient delay calls for research into patient awareness of cancer. For all delay components, special focus should be given to the $4^{\text {th }}$ quartile of patients with the longest time intervals and we need research into the quality of the diagnostic work-up process. We found large variations in delay for different types of cancer. Improvements should therefore target both the population at large and the specific needs associated with individual cancer types and their symptoms.
\end{abstract}

\section{Background}

The time interval from first symptom to start of treatment (i.e. surgery, chemotherapy) is often labelled delay even if parts of this delay are unavoidable. Delay in cancer diagnosis is common and long delay is associated with significant mental strain and possibly a worsened prognosis [1-3]. Although the exact effect of delay on clinical outcomes remains unclear and varies between cancers, it is generally accepted that total delay should be as short as possible [4-11]. British studies attribute that long delay may account for 5-10,000 extra deaths in the UK $[2,12]$. Only a few studies have analyzed in detail how delay is related to patients' health-seeking behaviour, general practitioners'

\footnotetext{
* Correspondence: rph@alm.au.dk

'Research Unit and Department of General Practice, Aarhus University,

Bartholins Allé 2, DK-8000 Aarhus C, Denmark

Full list of author information is available at the end of the article
}

(GPs') clinical performance and system-related factors such as logistics, waits and administrative procedures. Moreover, previous studies have covered only one or few specific cancer types [13-18]. Cancer represents one of the most severe diseases requiring the concerted effort of the entire care system. It is therefore an excellent candidate for a study of the interplay between the elements forming part of the overall clinical pathway. Knowledge of this may enable targeted efforts to improve the organization of care. The aim of this study was to conduct a population-based cohort study examining patient-, GP- and system-related delay and the extent to which delays vary by cancer type.

\section{Methods}

Study design

We performed a cohort study in the Danish County of Aarhus, which has 640,000 inhabitants, approx. 3,000

\section{Biomed Central}


- Denmark has a tax-financed health care system with free access to medical advice and treatment in general practices and hospitals. - All GPs in Denmark are independent contractors with the public health service and are remunerated on a mixed fee for service and capitation basis.

- Almost all (98\%) citizens are listed with a particular general practice which they have to consult for advice and treatment. The practice list size is on average 1,550 patients per GP (including children).

- GPs act as gatekeepers to investigations and hospital referrals.

Figure 1 The Danish health care system.

new cancer cases per year and approx. 500 GPs. Denmark's publicly funded health-care system provides free access to primary care and outpatient and hospital care (Figure 1). More than $98 \%$ of the Danish citizens are registered with a GP $[19,20]$. GPs function as gatekeepers to the rest of the health-care system, carrying out initial diagnostic investigations including referral to initial $\mathrm{x}$-ray and endoscopic procedures When indicated, they refer patients to hospitals or outpatient clinics, thus delegating further responsibility to secondary care. Danish GPs are required to keep detailed electronic records.

We included all newly diagnosed cancer patients during the 1-year period from 1 September 2004 to 31 August 2005. Patients younger than 18 years and patients with non-melanoma skin cancers were excluded. Patients were enrolled based on computerised data from the county hospital discharge registry (HDR), which for each hospital admission and outpatient visit records the patient's civil registration number (CRN), dates of admission and discharge, surgical procedure(s) performed and discharge diagnoses classified according to the international classification of diseases (ICD-10). We included all patients listed in the registry during the study period with incident cancer diagnoses, i.e. we excluded those with a recurrent cancer. Patients with previous cancer, but of another type, were regarded as incident cases. We then linked the HDR data to the county's Health Service Registry (HSR) in order to identify each patient's GP. The personal identifier used to link records to individuals across Danish registries is the CRN, which is assigned to all Danish citizens [21].

\section{Ethics approval}

According to the Scientific Ethics Committee in the County of Aarhus, the project did not need approval by the Danish Biomedical Research Ethics Committee System. The study was approved by the Danish Data Protection Agency and the Danish National Board of Health.

\section{Data collection}

A questionnaire was sent to the GP of each patient identified in the HDR. The GP was asked to confirm the diagnosis and to give a detailed description of the patient's diagnostic pathway using the dates reported in the medical record and the mandatory discharge letters from hospitals and specialists which report the date of first admission, the date of diagnosis and of first treatment. Furthermore, the GP provided the dates of the first patient symptoms (adherent to the actual cancer disease) as reported to the GP by the patient, the first presentation to the GP/practice, the initiation of diagnostic procedures, hospital referral, the first hospital visit, the diagnosis and the treatment start. Non-responders received a reminder after three weeks. The questionnaire was pilot-tested by the scientific staff and lay persons at the Department and Research Unit for General Practice, Aarhus and by 40 GPs from Vejle County, Denmark (purposefully selected by gender, age and practice location) [22].

\section{Outcome measures}

In accordance with most other research we used the term delay when calculating the different time intervals from first symptom to treatment start. Delay was 
calculated from the dates entered in the questionnaires by the GPs. Delay was divided into three delay stages. (1) Patient delay: Time from first perceived patient symptom until first presentation to the GP; (2) GP delay: Period from first presentation until initiation of an investigation of potentially cancer-related symptoms, i.e. biopsy, referral to imaging diagnostic, endoscopy or to other health-care professionals; (3) System delay: Time from the start of the GP-initiated investigation until the start of treatment. System delay was further divided into delay encountered in the primary health care sector (GP retaining responsibility for the patient) and in the secondary health care sector (the patient is no longer the responsibility of the GP) (Figure 2). System delay was defined in this way to be able to analyse to which extent cancer was seen and acted upon as an acute disease. In addition, total delay was defined as the interval from the first perceived patient symptom until treatment start.

We first computed delay for all cancer types and then for the 10 most frequent cancers found among the patients. The delay data are presented as medians and interquartile intervals (IQIs). The Wilcoxon rank-sum test was used to compare delay for those patients whose GPs were involved in the diagnostic investigation and those whose GPs were not. A P-value of 0.05 or less was used to signify statistical significance. Data were analysed using Stata software, version 11 (StataCorp, College Station, Tex).

\section{Results}

\section{Descriptive data}

A total of 2,212 questionnaires were completed. A total of 467 out of 543 physicians from 255 general practices participated in the study. On average, they filled in questionnaires on 4.7 patients (range 1-15, median 4). The physician response rate was $83 \%$ (Figure 3 ). No significant differences were found between the participating and non-participating physicians concerning gender, practice organization and years since graduation. GPs were involved in the diagnostic pathway in 1,892 (86\%) of the 2,212 cancer cases. For the remaining 320 cancer cases, we could only calculate system delay in the secondary health-care sector because they were admitted directly to the hospital by out-of-hours or accident and emergency services (A\&E), often for acute-onset symptoms. Table 1 shows the distribution of the 10 most frequent cancers diagnosed in Denmark [23] compared with the cancer distribution by type in our study.

\section{Delay data}

Table 2 shows the different delay stages for all cancers and for the 10 most frequent cancers diagnosed among study patients. Overall, among patients with complete questionnaire data the median total delay was 98 days (IQI 57 to 168), the median patient delay was 21 days (IQI 7 to 56 ), the median GP delay was 0 days (IQI 0 to 2) and the median system delay was 55 days (IQI 32 to 93). The period

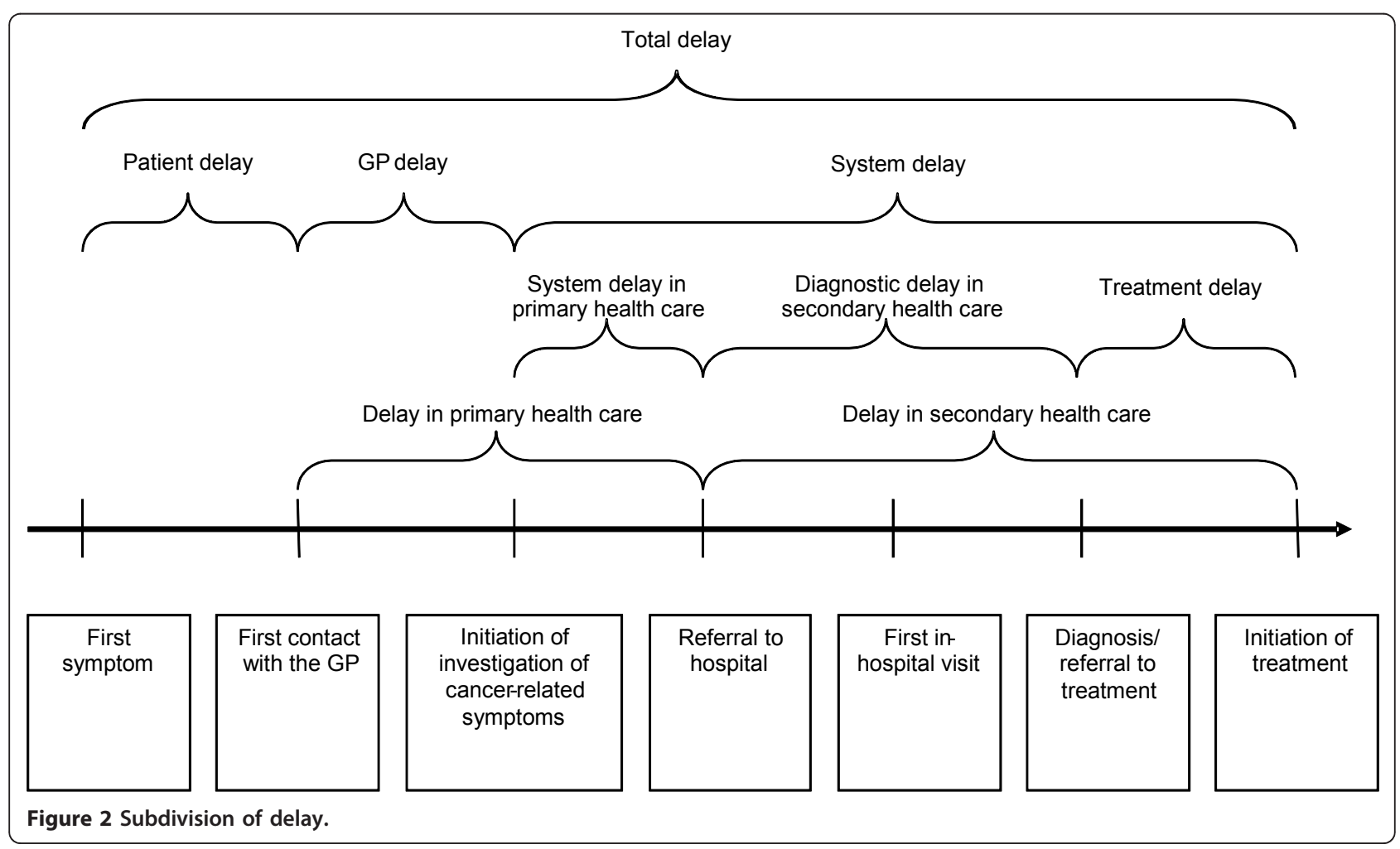




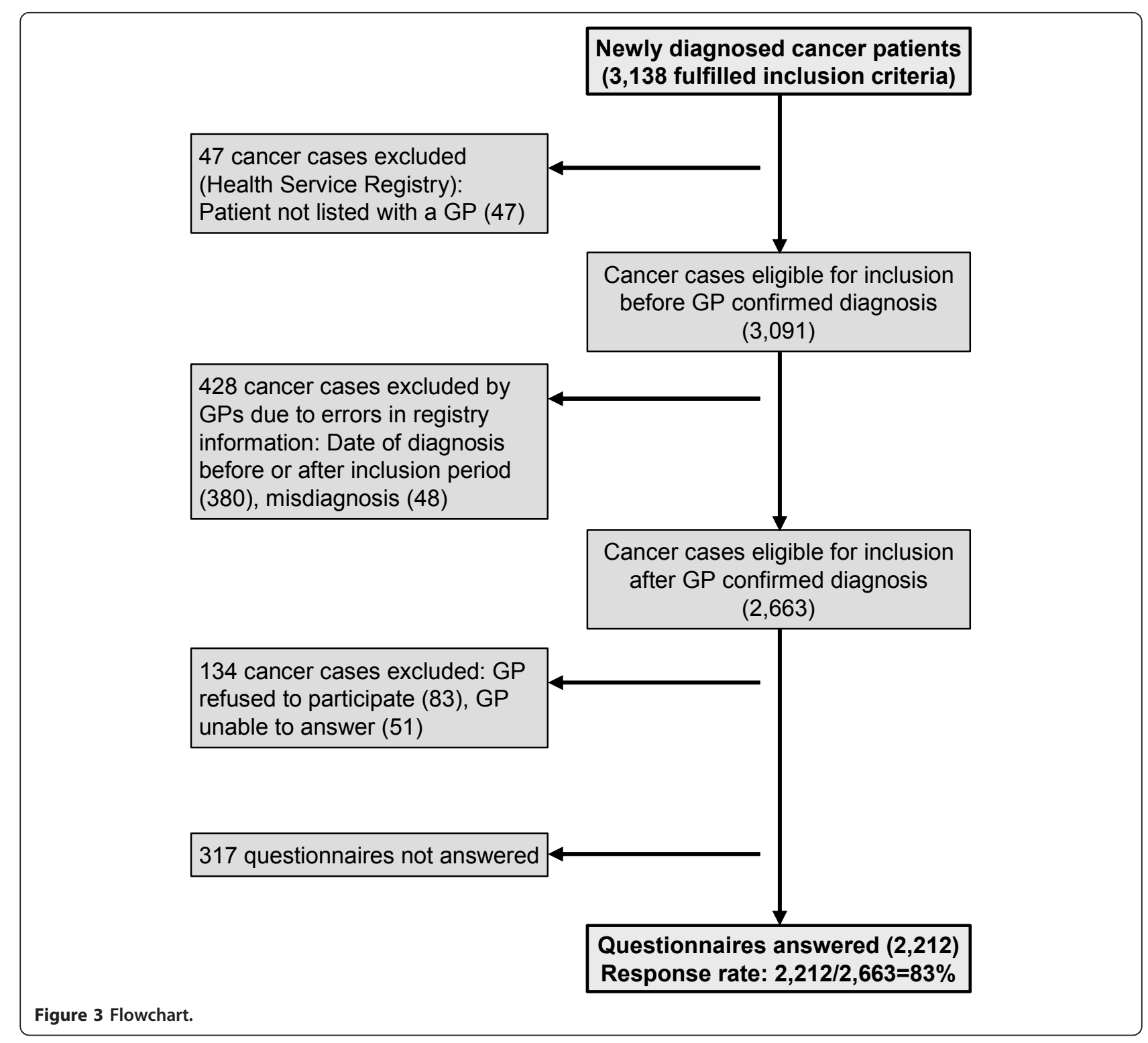

from referral to treatment (system delay in secondary health care) accounted for most of the system delay (median 46 days, IQI 26 to 78), while system delay in primary health care was minimal (median 0 days, IQI 0 to 12 ). Patients who saw their GPs prior to diagnosis experienced a statistically significantly $(Z=3.257, P=0.001)$ longer system delay in secondary health care (median 46 days, IQI 26 to 78) than those who were admitted directly to the hospital (median 37 days, IQI 17 to 63).

The shortest total delay was seen among patients with ovarian cancer (median 60 days, IQI 45 to 112); the second shortest delay was seen among patients with breast cancer (median 65 days, IQI 39 to 106). The longest total delay was found among patients with prostate (median 130, IQI 89 to 254) and bladder cancer (median 134, IQI
93 to 181) (Table 2). As shown in Figure 4, the $4^{\text {th }}$ quartile of patients experienced long patient, GP, system and total delay. Non-response analysis revealed no major differences between participating and non-participating physicians in terms of their cancer patients' age, gender or distribution of cancer diagnoses.

\section{Discussion}

We identified a median total delay of 98 days and a total delay exceeding 168 days among 1/4 of the patients. Patient and system delay accounted for most of the total delay. Even if the median GP delay was 0 days, a considerable proportion of the patients experienced a long GP-related delay. We found much variation in delay by cancer type. As expected, patients who saw their GPs prior to diagnosis 
Table 1 The number and the distribution of the 10 most frequent cancers diagnosed in Denmark and the cancer distribution by type in the study

\begin{tabular}{|c|c|}
\hline Cancers in DK ( $N=33501$ in 2003)* & Cancers in this study $(\mathrm{N}=2212)$ \\
\hline 1. Breast cancer (4027 - 12.0\%) & 1. Lung cancer (328 - 14.8\%) \\
\hline 2. Colorectal cancer (3576 - 10.7\%) & 2. Breast cancer (311 - 14.1\%) \\
\hline 3. Lung cancer (3500 - 10.4\%) & 3. Colorectal cancer (291 - 13.2\%) \\
\hline 4. Prostate cancer (2378 - 7.1\%) & 4. Prostate cancer (214 - 9.7\%) \\
\hline 5. Bladder cancer (1710 - 5.1\%) & 5. Melanoma (131 - 5.9\%) \\
\hline 6. Melanoma (1222 - 3.6\%) & 6. Bladder cancer (80 - 3.6\%) \\
\hline 7. CNS cancer (898 - 2.7\%) & 7. Non-Hodgkin's lymphoma (65 - 2.9\%) \\
\hline 8. Non-Hodgkin's lymphoma (828 - 2.5\%) & 8. Pancreas cancer (63 - 2.8\%) \\
\hline 9. Pancreas cancer (700 - 2.1\%) & 9. Ovarian cancer (59-2.7\%) \\
\hline 10. Leukaemia (694 - 2.1\%) & 10. Corpus uteri cancer (47 - 2.1\%) \\
\hline
\end{tabular}

* Including cancers in patients younger than 18 years

experienced longer delays than those who accessed specialist care directly.

In this paper we alternate between the terms "delay" and "time interval". Strictly speaking, the use of the term "delay" is often inappropriate as part of the time interval is unavoidable, and therefore the term "time interval" is often more correct. As delay is still widely used in the literature we have for comparable reasons continued to use this term, but future investigations might more consequently change the term to time interval.

The study covered the entire population above 17 years with newly diagnosed cancer in a large catchment area counting more than 600,000 inhabitants. The study is thus based on data on the total health-care performance in relation to cancer within a region during a 1-year period.

We reduced selection bias by using registry information to identify potential study participants independently of the participating GPs and hospital physicians. The excellent response rate (83\%) limits a possible selection bias; but, still, non-responding GPs may have seen patients with special diagnostic pathways, although non-response analysis revealed no major differences between participating and non-participating physicians in terms of their cancer patients' age, gender or distribution of cancer diagnoses. The description of socioeconomic patient characteristics associated with delay was not within the scope of this article, but this issue is covered in another article [24].

We further assured that only eligible patients were included by requesting that their GPs confirmed their diagnoses. Given the uniform organisation of health care throughout Denmark, we consider our results representative of the country as a whole. We cannot determine whether our findings are representative of other cultural settings or health-care systems in other counties. We recognize that the sample sizes of some of the delay calculations (especially total delay) for 6 of the 10 cancer types in the study (Table 2) are small (due to missing data and a small number of these cancers in Denmark). This may have affected the IQIs and evidently the generalisability of the results.

Minimisation of recall bias is a key prerequisite for the validity of our findings. We therefore encouraged the GPs to consult their electronic patient files including the discharge letters when filling in the questionnaires. Still, lack of complete information in some questionnaires may have introduced information bias. We anticipate that this bias tends to underestimate the reported delay, which may especially be the case for GP-reported delay. In another paper we have shown that it is difficult to define the time of symptom onset [25]. However, we do not yet know whether the patients' or the GPs' estimates are the most correct ones.

\section{Comparison of findings with previous literature}

Seen from a health services planning and a research and population perspective, it is relevant to include all cancers to be able to formulate a hypothesis about the need to focus on patient awareness of symptoms and access to diagnostic work-up of serious disease. However, our data on the specific cancer types also emphasise the need for detailed analyses of each specific cancer. We also need more research on the influence of symptom presentation in relation to delay [26]. A previous survey from the same region by Bjerager [13] showed that most delay in diagnosing lung cancer was attributable to system delay, which is consistent with our findings.

Our total delay findings accord with those of Allgar and Neal [17] who investigated patient-reported delay for six cancer types in a large population of UK cancer patients. However, in contrast to our results, they found that the main problem was patient and primary care delay. This discrepancy may be attributed to differences in the English and Danish health care systems in terms of culture, organisation and capacity, and to differences in study design and definitions of delay stages. Our broad definition of system delay encompassed not only time to 
Table 2 Delay (in days) for all and the 10 most frequent cancers in the study when the GP was involved in the diagnostic investigation process

\section{System delay}

Total delay Patient delay GP delay

System delay in secondary health care

System delay in secondary health care (GP not involved)

\begin{tabular}{|c|c|c|c|c|c|c|c|c|c|c|c|c|c|c|c|c|c|c|c|c|c|c|c|c|c|c|c|}
\hline \multirow{3}{*}{$\begin{array}{l} \\
\text { Cancer type (Cancer } \\
\text { cases, GP involved/Cancer } \\
\text { cases, GP not involved) }\end{array}$} & \multirow[b]{3}{*}{$\mathrm{N}$} & \multirow[b]{3}{*}{ Median } & \multirow[b]{3}{*}{$|\mathrm{IQ}|^{*}$} & \multirow[b]{3}{*}{$\mathrm{N}$} & \multirow[b]{3}{*}{ Median } & \multirow[b]{3}{*}{ IQI } & \multirow[b]{3}{*}{$\mathrm{N}$} & \multirow[b]{3}{*}{ Median } & \multirow[b]{3}{*}{ IQI } & \multirow{2}{*}{\multicolumn{3}{|c|}{$\begin{array}{c}\text { Total system } \\
\text { delay }\end{array}$}} & \multirow{2}{*}{\multicolumn{3}{|c|}{$\begin{array}{l}\text { System delay in } \\
\text { primary health } \\
\text { care }\end{array}$}} & \multirow{2}{*}{\multicolumn{6}{|c|}{$\begin{array}{cc}\begin{array}{c}\text { System delay in } \\
\text { secondary health } \\
\text { care }\end{array} & \begin{array}{c}\text { Diagnostic delay } \\
\text { in secondary } \\
\text { health care }\end{array}\end{array}$}} & \multirow{2}{*}{\multicolumn{3}{|c|}{ Treatment delay }} & \\
\hline & & & & & & & & & & & & & & & & & & & & & & & & & & & \\
\hline & & & & & & & & & & $\mathrm{N}$ & Median & IQI & $\mathrm{N}$ & Median & IQI & $\mathrm{N}$ & Median & IQI & $\mathrm{N}$ & Median & IQI & $\mathrm{N}$ & Median & IQI & $\mathrm{N}$ & Median & IQI \\
\hline All cancers $(1892 / 320)$ & 936 & 98 & $\begin{array}{l}57- \\
168\end{array}$ & 1237 & 21 & $\begin{array}{l}7- \\
56\end{array}$ & 1877 & 0 & $\begin{array}{l}0- \\
2\end{array}$ & 1422 & 55 & $\begin{array}{l}32- \\
93\end{array}$ & 1874 & 0 & $\begin{array}{l}0- \\
12\end{array}$ & 1412 & 46 & $\begin{array}{l}26- \\
78\end{array}$ & 1823 & 29 & $\begin{array}{l}14- \\
57\end{array}$ & 1403 & 14 & $\begin{array}{l}0- \\
28\end{array}$ & 174 & 37 & $\begin{array}{l}17- \\
63\end{array}$ \\
\hline Breast cancer (291/20) & 159 & 65 & $\begin{array}{l}39- \\
106\end{array}$ & 168 & 14 & $\begin{array}{l}0- \\
56\end{array}$ & 289 & 0 & $\begin{array}{c}0- \\
0\end{array}$ & 269 & 40 & $\begin{array}{c}25- \\
59\end{array}$ & 287 & 0 & $\begin{array}{c}0- \\
0\end{array}$ & 268 & 37 & $\begin{array}{c}22- \\
51\end{array}$ & 281 & 21 & $\begin{array}{l}13- \\
36\end{array}$ & 266 & 12 & $\begin{array}{l}4- \\
20\end{array}$ & 10 & 29 & $\begin{array}{l}23- \\
38\end{array}$ \\
\hline Colorectal cancer (254/37) & 159 & 109 & $\begin{array}{l}65- \\
194\end{array}$ & 187 & 28 & $\begin{array}{l}14- \\
56\end{array}$ & 254 & 0 & $\begin{array}{l}0- \\
6\end{array}$ & 212 & 56 & $\begin{array}{l}34- \\
87\end{array}$ & 254 & 0 & $\begin{array}{l}0- \\
10\end{array}$ & 216 & 48 & $\begin{array}{l}28- \\
71\end{array}$ & 251 & 30 & $\begin{array}{l}15- \\
50\end{array}$ & 215 & 14 & $\begin{array}{l}0- \\
28\end{array}$ & 24 & 15 & $\begin{array}{l}3- \\
30\end{array}$ \\
\hline Lung cancer (253/75) & 128 & 108 & $\begin{array}{l}82- \\
167 \\
\end{array}$ & 182 & 28 & $\begin{array}{l}7- \\
56 \\
\end{array}$ & 251 & 0 & $\begin{array}{l}0- \\
9\end{array}$ & 182 & 69 & $\begin{array}{l}47- \\
96\end{array}$ & 250 & 7 & $\begin{array}{l}0- \\
18 \\
\end{array}$ & 181 & 55 & $\begin{array}{l}36- \\
79 \\
\end{array}$ & 246 & 27 & $\begin{array}{l}14- \\
46\end{array}$ & 182 & 23 & $\begin{array}{l}8- \\
36\end{array}$ & 40 & 51 & $\begin{array}{l}27- \\
76 \\
\end{array}$ \\
\hline Prostate cancer (190/24) & 73 & 130 & $\begin{array}{l}89- \\
254\end{array}$ & 110 & 28 & $\begin{array}{c}0- \\
112\end{array}$ & 186 & 0 & $\begin{array}{l}0- \\
6\end{array}$ & 117 & 102 & $\begin{array}{l}55- \\
151\end{array}$ & 187 & 6 & $\begin{array}{l}0- \\
18\end{array}$ & 115 & 75 & $\begin{array}{l}44- \\
135\end{array}$ & 183 & 80 & $\begin{array}{l}44- \\
110\end{array}$ & 114 & 9 & $\begin{array}{l}0- \\
29\end{array}$ & 16 & 83 & $\begin{array}{l}48- \\
139 \\
\end{array}$ \\
\hline Melanoma (122/9) & 38 & 114 & $\begin{array}{l}79- \\
279\end{array}$ & 40 & 70 & $\begin{array}{l}28- \\
196\end{array}$ & 122 & 0 & $\begin{array}{l}0- \\
0\end{array}$ & 114 & 39 & $\begin{array}{l}22- \\
65\end{array}$ & 122 & 0 & $\begin{array}{l}0- \\
15\end{array}$ & 112 & 27 & $\begin{array}{l}15- \\
54\end{array}$ & 117 & 20 & $\begin{array}{l}0- \\
42\end{array}$ & 110 & 13 & $\begin{array}{l}0- \\
23\end{array}$ & 1 & 49 & \\
\hline Bladder cancer (73/7) & 32 & 134 & $\begin{array}{l}93- \\
181\end{array}$ & 52 & 14 & $\begin{array}{l}0- \\
28\end{array}$ & 72 & 0 & $\begin{array}{l}0- \\
10\end{array}$ & 43 & 91 & $\begin{array}{l}52- \\
119\end{array}$ & 71 & 2 & $\begin{array}{l}0- \\
19\end{array}$ & 42 & 80 & $\begin{array}{l}45- \\
113\end{array}$ & 68 & 62 & $\begin{array}{l}35- \\
87\end{array}$ & 43 & 0 & $\begin{array}{l}0- \\
20\end{array}$ & 4 & 51 & $\begin{array}{l}22- \\
75\end{array}$ \\
\hline $\begin{array}{l}\text { Non-Hodgkin's lymphoma } \\
(54 / 11)\end{array}$ & 29 & 78 & $\begin{array}{l}58- \\
118\end{array}$ & 43 & 21 & $\begin{array}{l}7- \\
42\end{array}$ & 53 & 0 & $\begin{array}{l}0- \\
3\end{array}$ & 34 & 60 & $\begin{array}{l}44- \\
86\end{array}$ & 54 & 2 & $\begin{array}{l}0- \\
14\end{array}$ & 34 & 55 & $\begin{array}{l}39- \\
73\end{array}$ & 51 & 36 & $\begin{array}{l}14- \\
68\end{array}$ & 34 & 12 & $\begin{array}{l}5- \\
29\end{array}$ & 4 & 38 & $\begin{array}{c}33- \\
51\end{array}$ \\
\hline Pancreas cancer (54/9) & 21 & 87 & $\begin{array}{l}49- \\
153\end{array}$ & 40 & 14 & $\begin{array}{l}7- \\
42\end{array}$ & 53 & 0 & $\begin{array}{l}0- \\
6\end{array}$ & 28 & 63 & $\begin{array}{l}27- \\
117\end{array}$ & 54 & 0 & $\begin{array}{l}0- \\
15\end{array}$ & 28 & 59 & $\begin{array}{l}25- \\
91\end{array}$ & 51 & 27 & $\begin{array}{l}11- \\
68\end{array}$ & 27 & 14 & $\begin{array}{l}0- \\
41\end{array}$ & 5 & 15 & $\begin{array}{l}10- \\
50\end{array}$ \\
\hline Ovarian cancer (47/12) & 32 & 60 & $\begin{array}{l}45- \\
112\end{array}$ & 38 & 21 & $\begin{array}{l}0- \\
35\end{array}$ & 47 & 0 & $\begin{array}{l}0- \\
2\end{array}$ & 40 & 30 & $\begin{array}{l}21- \\
49\end{array}$ & 47 & 0 & $\begin{array}{l}0- \\
8\end{array}$ & 40 & 26 & $\begin{array}{l}20- \\
43\end{array}$ & 45 & 21 & $\begin{array}{l}12- \\
31\end{array}$ & 39 & 1 & $\begin{array}{l}0- \\
21\end{array}$ & 9 & 40 & $\begin{array}{l}20- \\
62\end{array}$ \\
\hline Corpus uteri cancer (41/6) & 35 & 99 & $\begin{array}{l}51- \\
22 \\
\end{array}$ & 35 & 21 & $\begin{array}{c}0- \\
140 \\
\end{array}$ & 41 & 0 & $\begin{array}{l}0- \\
0 \\
\end{array}$ & 41 & 64 & $\begin{array}{l}41- \\
106 \\
\end{array}$ & 41 & 0 & $\begin{array}{c}0- \\
1 \\
\end{array}$ & 41 & 60 & $\begin{array}{l}32- \\
101 \\
\end{array}$ & 39 & 38 & $\begin{array}{l}23- \\
79\end{array}$ & 39 & 7 & $\begin{array}{l}0- \\
14\end{array}$ & 3 & 59 & $\begin{array}{l}28- \\
77\end{array}$ \\
\hline Others $(513 / 110)$ & 233 & 96 & $\begin{array}{l}56- \\
178\end{array}$ & 342 & 21 & $\begin{array}{l}7- \\
56\end{array}$ & 509 & 0 & $\begin{array}{l}0- \\
6\end{array}$ & 338 & 63 & $\begin{array}{l}35- \\
110\end{array}$ & 507 & 0 & $\begin{array}{l}0- \\
11\end{array}$ & 335 & 52 & $\begin{array}{l}29- \\
93\end{array}$ & 491 & 27 & $\begin{array}{l}12- \\
55\end{array}$ & 334 & 17 & $\begin{array}{l}0- \\
34\end{array}$ & 58 & 32 & $\begin{array}{l}13- \\
62\end{array}$ \\
\hline
\end{tabular}

$\mathrm{N}$ in each column is the number of answers with complete data. Last column shows system delay in secondary health care when the GP was not involved in the diagnostic investigation process

${ }^{*} \mathrm{Q} \mathrm{Q} \mathrm{I}=$ interquartile interval 

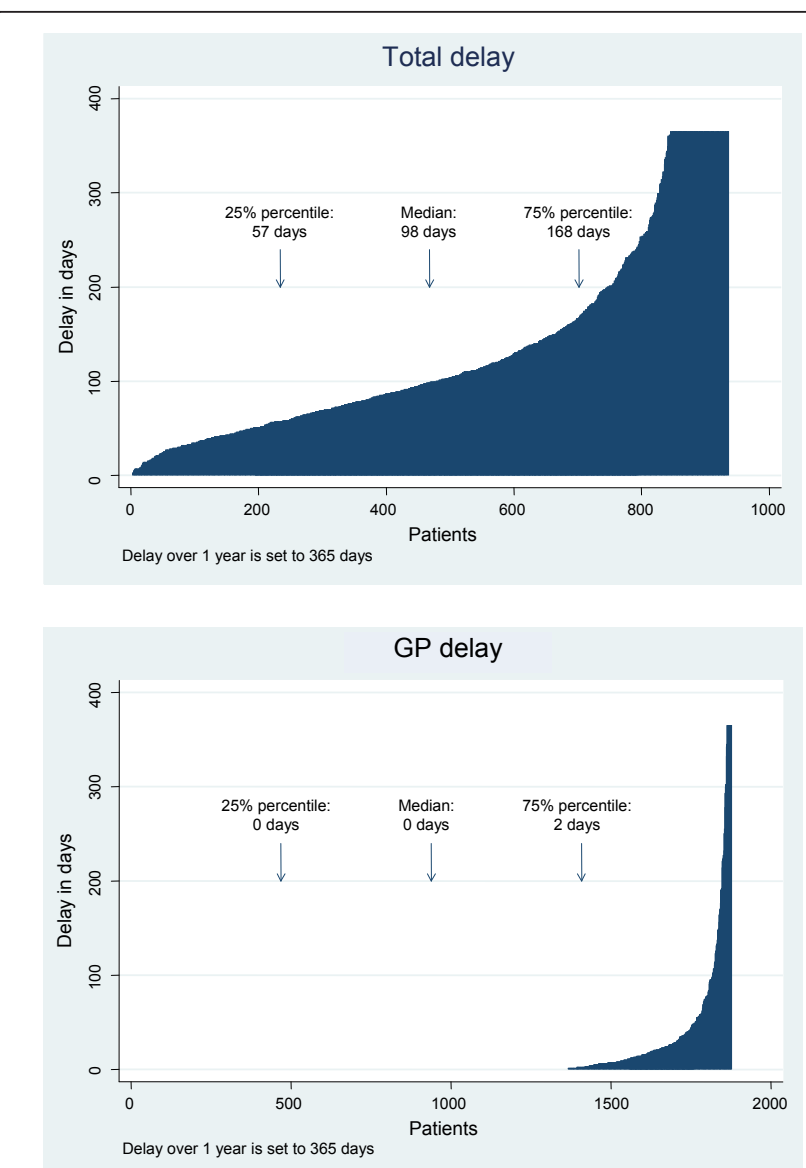
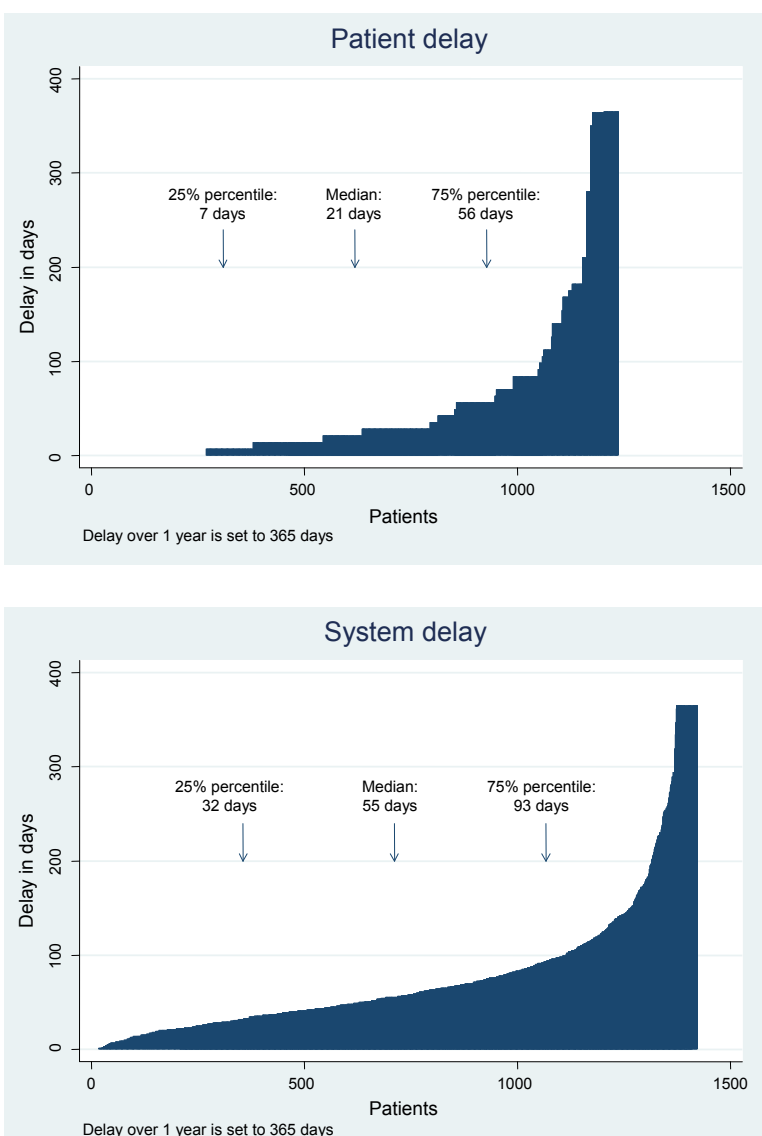

Figure 4 Total, patient, GP and system delay. Delay (in days) for each patient is shown in the figures.

diagnosis, but the time to start of treatment, as we expected a significant delay between diagnosis and treatment initiation. We need an internationally agreed definition on delay stages (Figure 2); a task that has been initiated in the UK National Initiative on Early Diagnosis of Cancer (NAEDI) and in the Cancer and Primary Care Research International Network (CA-PRI) [2,27].

\section{Implications of the study}

Cancer is a serious disease. The diagnostic evaluation is complex and often conducted in a sequential process, which may explain the long system delay. However, another explanation may be that Danish cancer patients have to wait longer for basic diagnostic investigations. Thus, another main finding of the present study was the long patient delay. We lack international knowledge about variation in patient awareness of symptoms and differences in delay and about the interaction between the health care structure and patient delay [28-30].

A recent paper showed that delay in diagnosis may have severe prognostic consequences and may partly explain the bad cancer outcome results in countries like the UK and Denmark [12]. Recent years have therefore seen the introduction of different initiatives to reduce system delay in the UK. However, a fast-track approach based on a GP's suspicion of cancer may not necessarily be effective as only some $50 \%$ of patients present to their GP with alarm symptoms [26,31]. The effect of seeing cancer as an acute disease and thereby circumventing administrative and capacity-driven bottlenecks in the pathway should be investigated. The fast-track approach was adopted in Denmark in 2008 [1,27], but it is too early to evaluate if this initiative has reduced systemrelated delay.

Further research is required to test whether improved access to diagnostic investigations and intra- and intersectoral cooperation within the health care sector will have an effect on the diagnosis of cancer.

Further analysis of the long delays characterising the $4^{\text {th }}$ quartile of patients requires clarification of the specific patient, GP and system characteristics that prolong delay. Our investigations invite the conclusion that a more precise research focus on early diagnosis of cancer is, indeed, warranted [2]. 


\section{Conclusions}

This study showed that patient and system delay account for most of the delay in cancer diagnosis. For all components of delay, special focus should be given to the $4^{\text {th }}$ quartile of the patients. Cancer prognosis may be improved if we focus on early diagnosis and improved clinical pathways.

\section{Funding}

The study was funded by grants from the Danish Agency for Science Technology and Innovation -the Danish Medical Research Council (22-03-0208), the Pharmaceutical Foundation of 1991 (139-2003), the Aarhus County Research Fund for the Clinical Development and Research in General Practice and Across the Primary and Secondary Health Care Sectors (4-01-2-2-02/4-01-2-5-00/4-01-3-04), and the Regional Clinical Research Unit of the Danish Cancer Society - Region North (KFE-AA-289-03). The funding sources had no involvement in the research process.

\section{Author details \\ ${ }^{1}$ Research Unit and Department of General Practice, Aarhus University, Bartholins Allé 2, DK-8000 Aarhus C, Denmark. ${ }^{2}$ The Danish Cancer Society and the Novo Nordisk Foundation Research Centre for Cancer Diagnosis in Primary Care, Bartholins Allé 2, DK-8000 Aarhus C, Denmark. ${ }^{3}$ Research Unit for General Practice, Aarhus University, Bartholins Allé 2, DK-8000 Aarhus C, Denmark. ${ }^{4}$ Research Unit for General Practice, Institute of Public Health, University of Southern Denmark, J.B. Winsløws Vej 9, DK-5000 Odense C, Denmark.}

\section{Authors' contributions}

FO conceived the study. The study was conducted by RPH in consultation with all the co-authors, IS performed the statistical analyses in consultation with the other authors. RPH drafted the manuscript and all authors contributed to critically revising the paper. Finally, all authors read and approved the submitted manuscript.

\section{Competing interests}

The authors declare that they have no competing interests.

Received: 24 February 2011 Accepted: 25 October 2011

Published: 25 October 2011

\section{References}

1. Rutqvist LE: Waiting times for cancer patients-a "slippery slope" in oncology. Acta Oncol 2006, 45:121-123.

2. Richards MA: The National Awareness and Early Diagnosis Initiative in England: assembling the evidence. Br J Cancer 2009, 101:S1-S4.

3. Risberg T, Sorbye SW, Norum J, Wist EA: Diagnostic delay causes more psychological distress in female than in male cancer patients. Anticancer Res 1996, 16:995-999.

4. Jensen AR, Nellemann HM, Overgaard J: Tumor progression in waiting time for radiotherapy in head and neck cancer. Radiother Oncol 2007, 84:5-10.

5. Afzelius $P$, Zedeler $K$, Sommer $H$, Mouridsen HT, Blichert-Toft M: Patient's and doctor's delay in primary breast cancer. Prognostic implications. Acta Oncol 1994, 33:345-351.

6. Richards MA, Westcombe AM, Love SB, Littlejohns P, Ramirez AJ: Influence of delay on survival in patients with breast cancer: a systematic review. Lancet 1999, 353:1119-1126.

7. Sainsbury R, Johnston C, Haward B: Effect on survival of delays in referral of patients with breast-cancer symptoms: a retrospective analysis. Lancet 1999, 353:1132-1135.
8. Jensen AR, Mainz J, Overgaard J: Impact of delay on diagnosis and treatment of primary lung cancer. Acta Oncol 2002, 41:147-152.

9. Myrdal G, Lambe M, Hillerdal G, Lamberg K, Agustsson T, Stahle E: Effect of delays on prognosis in patients with non-small cell lung cancer. Thorax 2004, 59:45-49.

10. Robinson E, Mohilever J, Zidan J, Sapir D: Colorectal cancer: incidence, delay in diagnosis and stage of disease. Eur J Cancer Clin Oncol 1986, 22:157-161.

11. Korsgaard M, Pedersen L, Sørensen HT, Laurberg S: Delay of treatment is associated with advanced stage of rectal cancer but not of colon cancer. Cancer Detect Prev 2006, 30:341-346.

12. Abdel-Rahman M, Stockton D, Rachet B, Hakulinen T, Coleman MP: What if cancer survival in Britain were the same as in Europe: how many deaths are avoidable? Br J Cancer 2009, 101:S115-S124.

13. Bjerager M: Delay in diagnosis and treatment of lung cancer [thesis]. 1 edition. Aarhus: Research Unit and Department of General Practice, Faculty of Health Sciences, University of Aarhus; 2006.

14. Wallace DM, Bryan RT, Dunn JA, Begum G, Bathers S: Delay and survival in bladder cancer. BJU Int 2002, 89:868-878.

15. Salomaa ER, Sallinen S, Hiekkanen H, Liippo K: Delays in the diagnosis and treatment of lung cancer. Chest 2005, 128:2282-2288.

16. Korsgaard M: Diagnostic Delay, Symptoms, and Stage of Colorectal Cancer: Population-based Observational Studies in Denmark [thesis]. 1 edition. Aarhus: Faculty of Health Sciences, University of Aarhus; 2005.

17. Allgar VL, Neal RD: Delays in the diagnosis of six cancers: analysis of data from the National Survey of NHS Patients: Cancer. Br J Cancer 2005, 92:1959-1970.

18. Jones RV, Dudgeon TA: Time between presentation and treatment of six common cancers: a study in Devon. Brit J Gen Pract 1992, 42:419-422.

19. Christiansen T: Organization and financing of the Danish health care system. Health Policy 2002, 59:107-118.

20. Olivarius NF, Hollnagel H, Krasnik A, Pedersen PA, Thorsen $H$ : The Danish National Health Register. A tool for primary health care research. Dan Med Bull 1997, 44:449-453.

21. Frank L: Epidemiology. When an entire country is a cohort. Science 2000 287:2398-2399.

22. Hansen RP: Delay in the diagnosis of cancer [PhD thesis]. 1 edition. Aarhus: Faculty of Health Sciences, University of Aarhus; 2008.

23. The Danish National Board of Health: The Cancer Registry 2003 [in Danish]. New figures from the National Board of Health 2005, 2005:1-19.

24. Hansen RP, Olesen F, Sorensen HT, Sokolowski I, Sondergaard J: Socioeconomic patient characteristics predict delay in cancer diagnosis: a Danish cohort study. BMC Health Serv Res 2008, 8:49.

25. Andersen RS, Vedsted P, Olesen F, Bro F, Sondergaard J: Patient delay in cancer studies: a discussion of methods and measures. BMC Health Serv Res 2009, 9:189.

26. Nielsen TN, Hansen RP, Vedsted P: Præsentation af symptomer i almen praksis hos patienter med cancer [Symptom presentation in cancer patients in general practice]. Ugeskr Laeger 2010, 172:2827-2831, Danish.

27. Olesen F, Hansen RP, Vedsted P: Delay in diagnosis: the experience in Denmark. British Journal of Cancer 2009, 101:S5-S8.

28. Andersen RS, Bro F, Olesen F, Vedsted P, Søndergaard J: The relation between health care systems and patient perceived access to health care. Scand J Prim Health Care 2011.

29. Austoker J, Bankhead C, Forbes LJ, Atkins L, Martin F, Robb K, Wardle J, Ramirez AJ: Interventions to promote cancer awareness and early presentation: systematic review. Br J Cancer 2009, 101:S31-S39.

30. Andersen RS, Paarup B, Vedsted P, Bro F, Soendergaard J: 'Containment' as an analytical framework for understanding patient delay: A qualitative study of cancer patients' symptom interpretation processes. Soc Sci Med 2010, 71:378-385.

31. Allgar VL, Neal RD, Ali N, Leese B, Heywood P, Proctor G, Evans J: Urgent GP referrals for suspected lung, colorectal, prostate and ovarian cancer. $\mathrm{Br} J$ Gen Pract 2006, 56:355-362.

Pre-publication history

The pre-publication history for this paper can be accessed here: http://www.biomedcentral.com/1472-6963/11/284/prepub

doi:10.1186/1472-6963-11-284

Cite this article as: Hansen et al:: Time intervals from first symptom to treatment of cancer: a cohort study of 2,212 newly diagnosed cancer patients. BMC Health Services Research 2011 11:284. 